\title{
Smart Water Dripping System for Agriculture/ Farming
}

\author{
D. Sowmya, R. Praveen Sam, K. Govardhan Reddy
}

\begin{abstract}
The main work uses an ARDUINO microcontroller that is programmed to obtain the input signal of varying moisture condition of the soil through the sensing association. Soil sensor is done by way of usage of an op-amp as a comparator which acts as an interface among the sensing arrangement and the microcontroller. Once the controller receives this sign, it generates an output that drives a relay for running the water pump. An LCD show is also interfaced to the microcontroller to show repute of the soil, temperature, $\mathrm{PH}$, WIFI and water pump.

Water shortage has been massive trouble for agriculture. This proposed concept is beneficial to the farmers to irrigate the farms successfully the usage of an electronic irrigation gadget based totally on soil temperature, moisture and $\mathrm{pH}$. Respective sensors are used to locate the soil water content material stage and based on this, and microcontroller drives the servo motor and pump. Irrigation fame is up to date to the database the use of PC. This method works utilizing putting in sensors within the subject to monitor the soil temperature, moisture and kind of soil, which transmits the data to the microcontroller for estimation of the correct amount of water as according to the requirements. The accumulated data is updated sometimes to the server and may be accessed through an Android app. The next watering of plant life may be managed the usage of the aforementioned app. Depending upon the form of soil and crop, the fertilizers are recommended by means of applying Naïve Bayes set of rules at the database. The estimated quantity of rain is predicted using weather forecasting using Web scraper, and the plants are watered for this reason, i.e., is a heavy rainfall is predicted then the device will routinely reduce the water supplied to the plants.
\end{abstract}

\section{INTRODUCTION}

The estimation is that in order to meet the meals and water requirements globally until 2020, the productivity of the prevailing land ought to be multiplied at an unparalleled price [1]. Overtly exploiting the groundwater and the boom in water-saving strategies over the past three decades has avoided the estimated shortage of meals production for the $1990 \mathrm{~s}$, but the situation continues to worsen as there has been fundamental exploitation of aquifers and discount within the satisfactory of water in many components of the growing international. There are multiplied pressure on present water allocations and has improved the significance of water control for the sustainability of irrigated agriculture. The objectives of this concept are: To optimize the water deliver to crops, to reduce manual intervention, to make the irrigation gadget smart, self-reliant and green.

The fundamental goal of this undertaking is to develop water pumping system capable of acting irrigation or watering project automatically and is powered by using a device.

Revised Manuscript Received on September 22, 2019

D.Sowmya, Mtech Student, G.Pulla Reddy Engineering College, Kurnoo dadireddysowmya98@gmail.com

Dr.R.Praveen Sam, Professor, G.Pulla Reddy Engineering College, Kurnool rpraveensam.cse@gprec.ac.in

Dr.K.Govardhan Reddy, Associate Professor, G.Pulla Reddy Engineering College, Kurnool govardhan.cse@gprec.ac.in
A moisture sensor within the soil is used to test the need for irrigation in order to operate a pump. In addition to the input from moisture sensor, Timer function in the microcontroller turned into additionally carried out to save you watering too frequently according to today. This ensures that the crop or plant in the discipline will no longer have growth issues because of overwatering. The goal of the mission is to increase a program via using microcontroller as to carry out the feature of preserving right stability of moisture within the soil and also to assemble sun-powered computerized irrigation system that runs with the usage of the moisture sensor, microcontroller and different required circuitry.

It provides better reliability and increases daily water volume. While pumping the water to the rural land, vegetation may be destroyed due to the inefficient utilization of the water recourses. This paper proposes the method which examines the water level within the tank and soil moisture content material and offers the command signal to the Arduino primarily based microcontroller to manipulate the outlet and the closing of the pump relying on the requirement.

It has been observed that the consistent with capita water availability in India has a lowering trend; subsequently, there is a want for a computerized irrigation system to utilize water effectively.

\section{LITERATURE REVIEW}

In India, agriculture performs a very vital role in the improvement of us of an as our economic system mainly primarily based on it. India ranks second globally in farm output. The most essential component for agriculture is timely and enough deliver of water. But due to unsure rainfall and water shortage inland reservoirs, we are not able to make the right use of agricultural resources. Also unplanned used of water effects into losing of water on massive proportion. With the boom in farm interest and competitive demand from private sectors, it has to turn out to be vital to saving money on the use of water. We can optimize the use of water with the aid of adopting sensorbased irrigation system. There are different irrigation systems used these days to reduce the dependency of rain. Due to the shortage of strength and mismanagement, inside the guide manipulate irrigation gadget many times vegetation are dry or flooded with water. So to keep away from this problem, a sensor base irrigation device is used. In the manual method, farmers commonly manipulate the electrical motors staring at the soil, crop and climate conditions by means of travelling the websites. Soil moisture sensor base irrigation gadget guarantees right moisture level within the soil for developing plant life in all season. 
In this system, the sensor is sensing the moisture content of soil and accordingly switches the pump motor on or off. The soil moisture sensor is found in the soil condition whether or not the soil is moist or dry. If land is dry, the pump motor will pump the water till the sector is wet that's continuously monitored through the microcontroller. The essential benefit of the soil moisture sensor is to make specific accurate measurements and farmer doesn't need to visit his farm to perform the pump. Same time, the use of this method microcontroller is sending a message on farmers cellular about pump popularity. For the operation of a sensor base irrigation machine, pump motor calls for power for pumping. In everyday life, there is a growing demand for power, but there may be a non-stop discount in current resources of fossils and fuels. According to the survey performed by way of the Bureau of Electrical Energy in India in 2011, there are around 18 million agricultural pump units and approximately 0.5 million new connections in keeping with year are mounted with current capacity 5HP. Total annual intake in agriculture area is 131 - ninety-six billion KWh (19\% of general power consumption). So, solar strength is handiest an answer to nowadays's an energy crisis. It is a perfect source of electricity in the global as it's miles environment pleasant and its unlimited availability. In reality, the amount of the Sun's power that reaches the Earth each minute is more than the power that the arena's populace

\section{DESIGN OF HARDWARE}

This chapter briefly explains about the hardware implementation of authentication of smart water dripping system for agriculture/farming. It discusses the circuit diagram of each module in detail.

\subsection{ARDUINO UNO}

The Arduino Uno is a microcontroller board primarily based on the ATmega328 (datasheet). It has 14 virtual enter/output pins (of which six may be used as PWM outputs), six analog inputs, a $16 \mathrm{MHz}$ ceramic resonator, a USB connection, an energy jack, an ICSP header, and a reset button. It incorporates the whole thing needed to guide the microcontroller; absolutely join it to a laptop with a USB cable or energy it with an AC-to-DC adapter or battery to get started out.

The Uno differs from all previous boards in that it does not use the FTDI USB-to-serial driver chip. Instead, it features the Atmega16U2 (Atmega8U2 up to version R2) programmed as a USB-to-serial converter. Uno board has a resistor pulling the $8 \mathrm{U} 2 \mathrm{HWB}$ line to floor, making it less complicated to position into DFU mode. Arduino board has the following new functions:

- 1.Zero pinouts: delivered SDA and SCL pins which might be close to to the AREF pin and two other new pins placed near to the RESET pin, the IOREF that permit the shields to conform to the voltage provided from the board. In destiny, guards will be like-minded each with the board that use the AVR, which perform with $5 \mathrm{~V}$ and with the Arduino Due that shows with three. $3 \mathrm{~V}$.

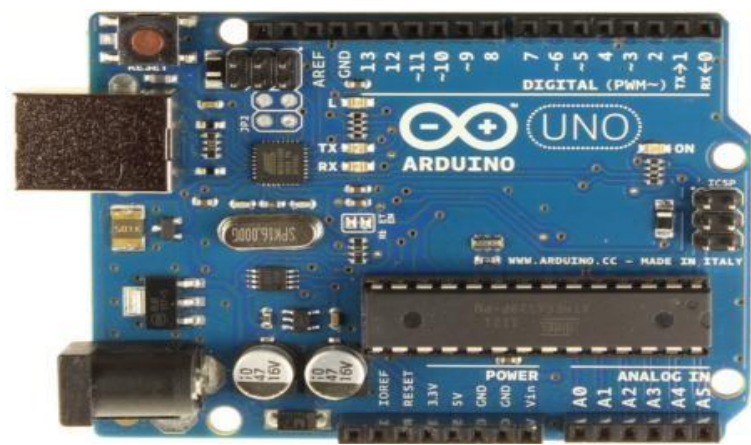

Fig1: ARDUINO UNO

\subsection{NodeMCU:}

NodeMCU is an open supply IoT platform. It includes firmware which runs on the ESP8266 Wi-Fi SoC from Espressif Systems, and hardware which is based at the ESP-12 module. The term "NodeMCU" with the aid of default refers to the firmware rather than the improvement kits. The firmware uses the Lua scripting language. It is primarily based on the eLua assignment, and built at the Espressif Non-OS SDK for ESP8266. It uses many open supply tasks, together with lua-cjson and SPIFFS.

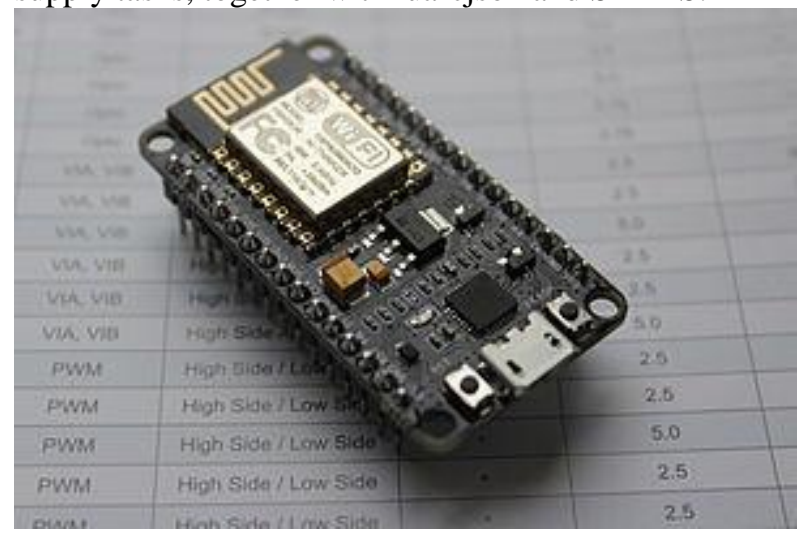

Fig2: NodeMCU

\subsection{POWER SUPPLY}

The strength components are designed to transform excessive voltage AC mains energy to a suitable low voltage supply for digital circuits and other devices. A power supply can be broken down into a sequence of blocks, every of which performs a specific function. A d.C strength supply which continues the output voltage steady no matter a.C mains fluctuations or load variations are referred to as "Regulated D.C Power Supply".

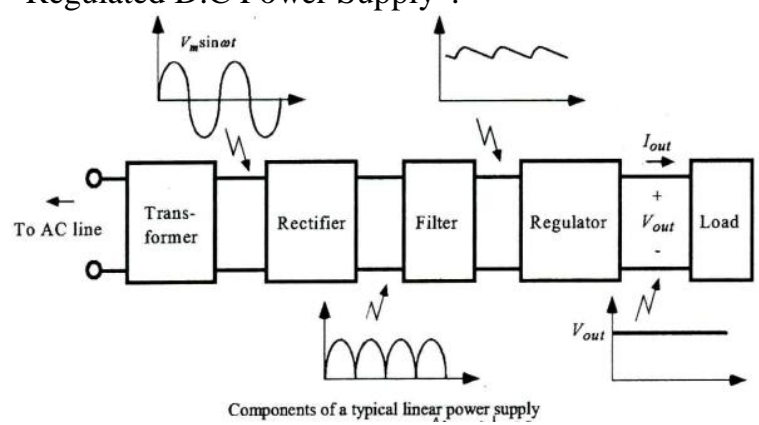

Fig3: Schematic Diagram of Power Supply 


\subsection{RELAYS}

We realize that most of the high cease industrial software devices have relays for their powerful working. Relays are simple switches which are operated each electrically and robotically. Relays include an electromagnet and additionally a fixed of contacts. The switching mechanism is executed with the help of the electromagnet. There also are different operating principles for operating. But they differ consistent with their applications. Most of the gadgets have the software of relays.

\section{Relay Basics}

The fundamentals for all the relays are identical. Take a look at a four-pin in relay proven beneath. There are hues shown. The green colour represents the manipulate circuit, and the crimson colour represents the burden circuit. A small manage coil is attached to the manipulate circuit. A switch is connected to the weight. This switch is controlled through the loop within the manage circuit. Now allow us to take the one of a kind steps that occur in a relay.

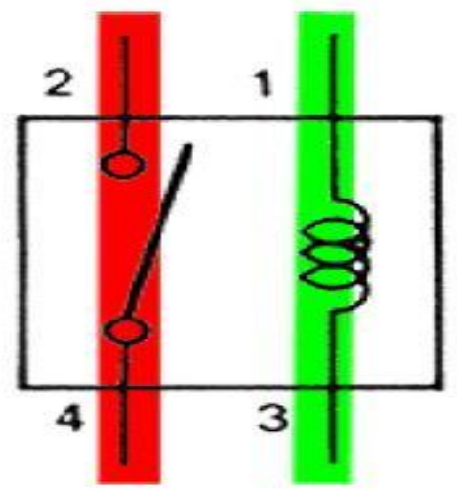

Fig4: relay operation

\subsection{LCD}

Liquid Crystal Display also called as LCD, may be very helpful in presenting person interface in addition to for debugging motive. The maximum generally used Character primarily based LCDs are mainly based on Hitachi's HD44780 controller or other which can be compatible with HD44580. The peak typically used LCDs observed inside the market these days are 1 Line, 2 Line or four Line LCDs that have only one controller and support a maximum of eighty characters, while LCDs helping more than eighty characters employ 2 HD44780 controllers

\section{Pin Description}

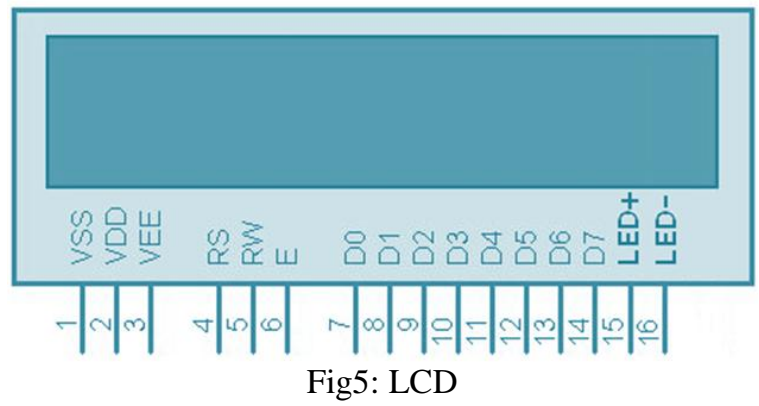

\subsection{TEMPERATURE SENSOR (LM35):}

In order to monitor the temperature continuously and compare this with the set temperature preprogrammed inside the microcontroller, initially this temperature cost needs to be study and fed to the microcontroller. This temperature fee must be sensed. Thus a sensor has to be used, and the sensor used in this task is LM35. It converts temperature price into electrical alerts.
LM35 series sensors are precision incorporated-circuit temperature sensors whose output voltage is linearly proportional to the Celsius temperature. The LM35 requires no external calibration since it's miles internally calibrated. The LM35 does not require any external calibration or trimming to offer usual accuracies of $\pm 1 / 4^{\circ} \mathrm{C}$ at room temperature and $\pm 3 / 4^{\circ} \mathrm{C}$ over a full - fifty-five to + a hundred and fifty ${ }^{\circ} \mathrm{C}$ temperature variety.

The LM35's low output impedance, a linear output, and specific internal calibration make interfacing to readout or manage circuitry in particular smooth. It may be used with single power components, or with plus and minus resources. As it draws most effective $60 \mu \mathrm{A}$ from its supply, it has very low self-heating, less than zero. $1^{\circ} \mathrm{C}$ in nonetheless air.
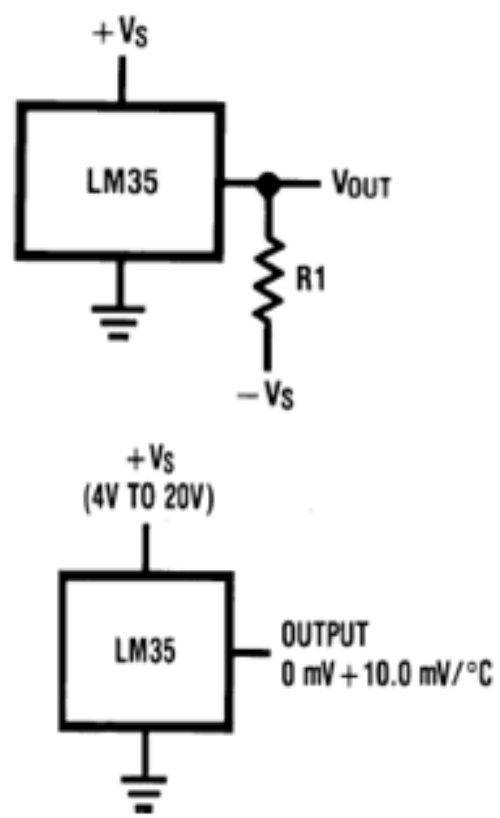

Fig6: LM35 sensor

\subsection{PH SENSOR}

A pH meter is a systematic tool that measures the hydrogen-ion pastime in water-primarily based answers, indicating its acidity or alkalinity expressed as $\mathrm{pH} .[2]$ The $\mathrm{pH}$ meter measures the difference in electrical capacity between a $\mathrm{pH}$ electrode and a reference electrode, and so the $\mathrm{pH}$ meter is every so often known as a "potentiometric $\mathrm{pH}$ meter". The distinction in electrical ability relates to the acidity or $\mathrm{pH}$ of the answer.[3] The $\mathrm{pH}$ meter is used in many programs ranging from laboratory experimentation to high-quality control.

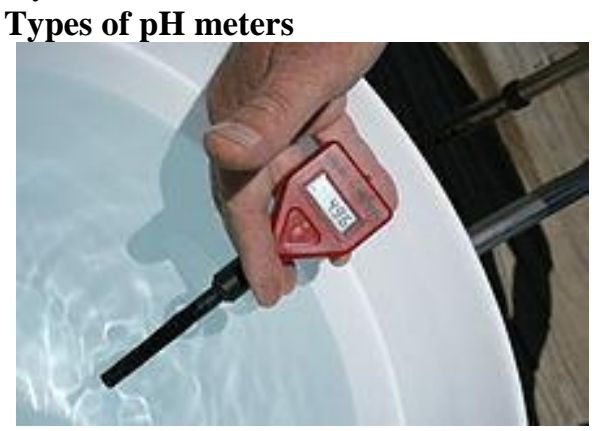

Fig7: pH meter 


\subsection{SOIL SENSOR}

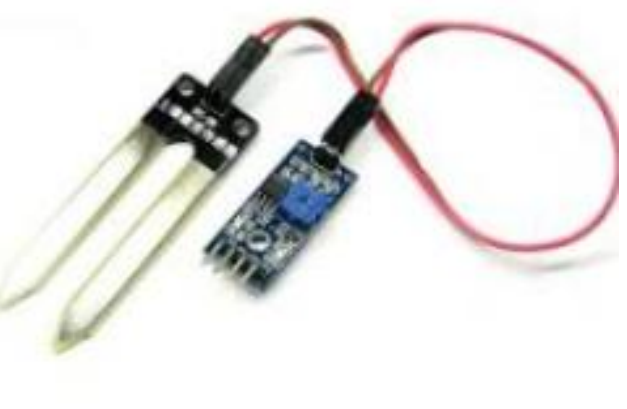

Fig8: soil moisture sensor for gardeners.

Soil moisture sensors degree the volumetric water content in the soil.[1] Since the direct gravimetric dimension of unfastened soil moisture requires disposing of, drying, and weighting of a sample, soil moisture sensors degree the volumetric water content not directly with the aid of the use of some other belongings of the soil, including electric resistance, dielectric regular, or interaction with neutrons, as a proxy for the moisture content material.

The relation between the measured assets and soil moisture have to be calibrated and may vary relying on environmental elements inclusive of soil kind, temperature, or electric conductivity. Reflected microwave radiation is suffering from the soil moisture and is used for far-flung sensing in hydrology and agriculture. Portable probe units can be utilized by farmers or gardeners.

Soil moisture sensors commonly consult with sensors that estimate volumetric water content. Another magnificence of sensors degree another asset of moisture in soils called water ability; those sensors are frequently referred to as soil water capability sensors and include tensiometers and gypsum blocks.

\section{PROJECT DESCRIPTION} identify the

This project ensures that the customers can quickly

\subsection{BLOCK DIAGRAM:}

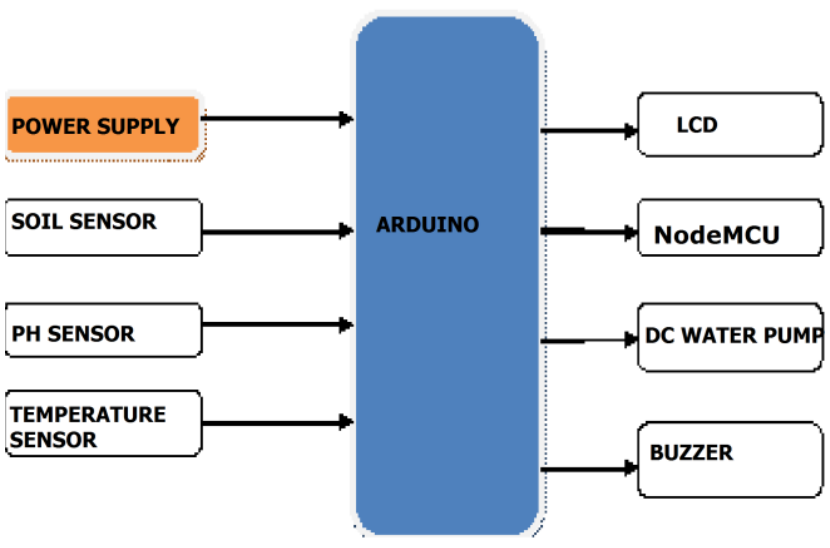

Fig9: block diagram

From the above discern Farmers begin to make use of various monitoring and controlled system an excellent way to increase the yield with the help of automation of agricultural parameters like temperature, humidity, soil moisture, carbon dioxide, light detection, soil $\mathrm{pH}$, and many others. Are monitored and managed systems that could assist the farmers in improving the yield.

1) $\mathrm{pH}$ Sensors: PH Sensors are used to measure the nutrient content material within the soil required for irrigation.

2) Temperature Sensors: It measures temperature in the range of zero-a hundred and ten diploma Celsius. It belongs to LM35 collection. It is RTD which goes at the concept of measuring resistance. More the resistance, extra the temperature.

3) Moisture Sensors: It measures the range from 0 $60 \%$. SM300 sensor is used. It measures the dielectric steady of the soil. Higher the dielectric regular, higher the moisture content material. This sensor will go back the resistance of soil: more the strength, much less the moisture content material and vice versa.

4) Water pump: It will be operated by way of the driver circuit, and it'll deliver water to the sector.

5) Power supply: 5V strength give is used.

\section{WORKING:}

Initially, the soil parameters are sensed by using the sensors and the values are handed to comparator on the way to evaluate the input values with the predefined tiers described within the database. The database includes upper sure and decreases bound of resistance values for frequently used vegetation in conjunction with class labels, which would be fertilizer names. Along with that, there will be another input desk where immediate values of sensor values can be stored, and Boolean output attribute value will be communicated to Arduino, so one can then decide whether or not to water the sphere or now not. Now the software application written can be carried out, and it's going to send a high signal to relay to replace the motor ON. In order to decide if the machine has didn't water the vegetation, the sensor values will be sensed now and again, and if there may be no trade within the benefits, then the system has failed. In case the device fails, the Android app will be notified and finally close down. Depending upon the sort of crop, the quantity of water is already known. Hence a timer will be set so that it will be used to water the vegetation. Once, the timer reaches 0 , and the water will be stopped. In the rainy season and from time to time in other seasons, because the soil will already incorporate a few quantities of water because of rainfall, there is no need for explicit watering. So the climatic conditions are monitored using climate forecasting sites. The forecast from the website (like sunny, cloudy, and so on.) are extracted using Web Scraping equipment [4].

This fee might be displayed on the Android app and depending upon those values. It'll be robotically determined whether or not or now not to water the vegetation. In some cases, the forecast won't be accurate, and then the farmer will be given a choice to override the water deliver manually. . 
For instance, if we take a sample of dry soil for testing, values of temperature and moisture sensed (sensors sends the resistance values of the land) might be high and consequently, the pump may be switched ON robotically. Whereas, if we take a sample of moist soil, the sensed values of temperature and moisture could below, and the motor remains OFF. The machine will calculate, and a decision will be taken for motor activation based on values displayed via android software. By using the data mining strategies at the database, fertilizers are recommended for the single crop.

\subsection{EXPERIMENTAL RESULTS:}

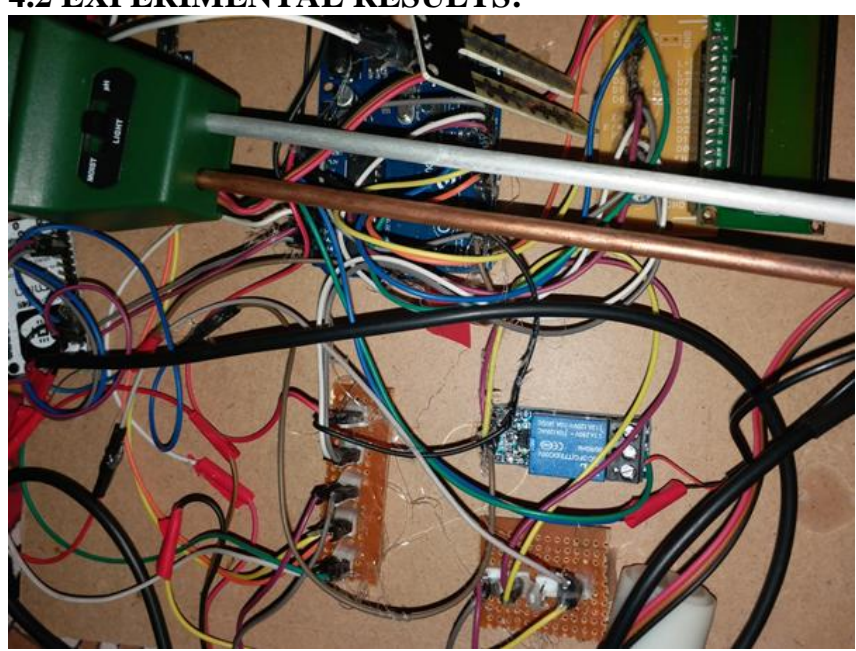

Fig10: Hardware Implementation

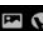

จ․,11 73\%日 7:13 pm

SMART WATER DRIPPING

SOIL MOISTURE :

1017

PH :

5

TEMPERATURE : 28 deg C

IR : NORMAL

\section{MOTOR}

FERTILIZER SUGGESTION

1) Conserve water: With the help of this system, you will control the quantity of water given to the fields. This can assist in managing the excess water that is wasted. 2) Avoidance of constant vigilance: There is minimal human intervention as the gadget takes into consideration the water content material level in the soil and consequently provides water. Hence, human beings need no longer always be in the sector. 3) Remote automation: The deliver of water may be controlled using an Android app. Hence, the farmer wants not to be present on the field to begin the water provide.

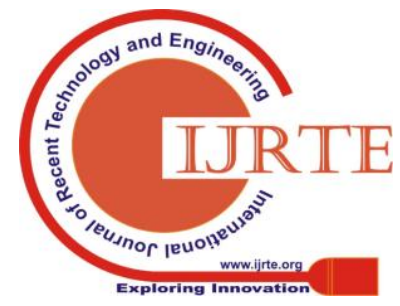




\section{CONCLUSION}

The proposed version is an automated gadget in an effort to display and control the water requirements within the discipline accurately. Smart irrigation gadget ensures really appropriate utilization of water. This architecture makes use of a microcontroller, which guarantees an increase in machine life lowering energy consumption. The device proposes a quick solution for the judicious utilization of water which has been a chief difficulty in growing international locations like India. The android machine makes it easy to access the complete machine

\section{FUTURE SCOPE}

1) In destiny, the device will estimate the irrigation cost and check the viability of the method. 2) Introduction of wireless sensors 3) More accurate thought of fertilizers using nutrient content. 4) Continuous vigilance of the sector for computerized watering without human intervention.

\section{REFERENCES}

[1] V. B. Shinde and S. S. Wandre, "Solar photovoltaic water pumping system for irrigation: A review", African Journal of Agricultural Research, Vol. 10, pp. 2267-2273, 2015. DOI 10.5897/AJAR2015.9879

[2] Mohanlal Kolhe, J. C. Joshi and D. P. Kothari, "Performance Analysis of a Directly Coupled Photovoltaic Water-Pumping System", IEEE Trans. on energy conversion, Vol. 19, pp. 613-618, 2004. DOI 10.1109/TEC.2004.82703.

[3] Nafisa Binte Yousuf, Khosru M. Salim, Rafid Haider, Md. Rajin Alam and Fatima Binte Zia, "Development of a Three Phase Induction Motor Controller for Solar Powered Water Pump", 2nd International Conference on the Developments in Renewable Energy Technology (ICDRET), Jan. 2012.

[4] J. V. Mapurunga Caracas, G. De Carvalho Farias, L. F. Moreira Teixeira and L. A. De Souza Ribeiro, "Implementation of a HighEfficiency, High-Lifetime, and Low-Cost Converter for an Autonomous Photovoltaic Water Pumping System", IEEE Trans. on industry applications, Vol. 50, pp. 631-641, 2014. DOI 10.1109/TIA.2013.2271214

[5] R. Krishnan, "Electric Motor Drives: Analysis, Modeling and Control", Prentice Hall Inc., New Jersey, 2001.

[6] Rajan Kumar and Bhim Singh, "Solar PV Array Fed Cuk ConverterVSI Controlled BLDC Motor Drive for Water Pumping", IEEE Power India International Conference (PIICON), Dec. 2014. DOI 10.1109/POWERI.2014.7117669

[7] Rajan Kumar and Bhim Singh, "Buck-Boost Converter Fed BLDC Motor Drive for Solar PV Array-Based Water Pumping", IEEE International Conference on Power Electronics, Drives and Energy Systems (PEDES), Dec. 2014 DOI - 10.1109/PEDES.2014.7042001

[8] Henry Shu-Hung Chung, K. K. Tse, S. Y. Ron Hui, C. M. Mok and M. T. Ho, "A Novel Maximum Power Point Tracking Technique for Solar Panels Using a SEPIC or Cuk Converter", IEEE Trans. on Power Electronics, Vol. 18, pp. 717-724, 2003. DOI 10.1109/TPEL.2003.810841

[9] Z. Hamidon, P. D. Abd. Aziz and N. H. Mohd Yunus, "Photovoltaic array modelling with P\&O MPPT algorithm in MATLAB", International Conference on Statistics in Science, Business, and Engineering (ICSSBE), Sept. 2012. DOI 10.1109/ICSSBE.2012.6396616

[10] https://greenpeacechallenge.jovoto.com/ideas/32221

[11] Muhammad H. Rashid, "Electric Renewable Energy Systems", Academic Press Inc, November 2015.

[12] https://www.arduino.cc/en/Guide/Introduction 